\title{
REFLEXÕES E CONTRIBUIÇÕES DO ESTÁGIO SUPERVISIONADO NO CURSO DE LICENCIATURA EM QUÍMICA DA UFPA
}

\section{REFLECTIONS AND CONTRIBUTIONS OF THE SUPERVISED INTERNSHIP IN THE UNDERGRADUATE CHEMISTRY COURSE AT UFPA}

Hebert Heitor Silva de Jesus ${ }^{1}$

ORCID iD: 0000-0001-7336-0574

Francisco Everdosa Tolosa ${ }^{2}$

ORCID iD: $\underline{0000-0001-5373-0443}$

Adriano Caldeira Fernandes ${ }^{3}$

ORCID iD: $\underline{0000-0001-5373-0443}$

\begin{abstract}
RESUMO
Diante da relevância que o estágio supervisionado possui em ser a ponte entre a teoria e a prática compete entendê-lo como atividade curricular essencial ao processo formativo das licenciaturas. Desse modo, o presente estudo averiguou se o estágio supervisionado realizado por licenciandos em Química da Universidade Federal do Pará (UFPA) se relaciona com a ideia de pesquisa voltada ao desenvolvimento da atividade pedagógica como meio de construção do perfil profissional do professor. Assim, investigou-se a realização do estágio dentro da formação inicial e continuada de professores, a fim de conhecê-lo a partir de uma realidade formativa. A coleta de dados deu-se pela discussão em grupo, com base em uma entrevista semiestruturada, teve-se conhecimento das necessidades, anseios e inquietações em face da formação e estágio supervisionado dos graduandos. Na análise percebeu-se que a componente curricular pouco tem contribuído ao processo de formação e o quanto é importante uma abordagem diferenciada para que seja produtiva. Assim, enfatiza-se a necessidade de ação colaborativa da tríade: Professor orientador da Universidade - Professor em Formação - Professor da Educação Básica; para que, seja possível a construção de uma prática transformadora desde os momentos iniciais.
\end{abstract}

Palavras-chave: Estágio supervisionado. Formação de professores. Perfil docente em Química. Educação em Ciências. Educação Química.

\begin{tabular}{|c|}
\hline ABSTRACT \\
\hline $\begin{array}{l}{ }^{1} \text { Licenciado em Química pela Universidade Federal do Pará. Professor da Rede Pública de Ensino do } \\
\text { Estado do Pará (SEDUC-PA), Belém, Pará, Brasil, Rod. Augusto Montenegro Km 10, s/n - Icoaraci } \\
66.820-000 \text {. E-mail: hebert.quimica@ @mail.com. } \\
{ }^{2} \text { Licenciado em Química pela Universidade Federal do Pará (UFPA). Colaborador de Química do } \\
\text { Centro de Ciências e Planetário do Pará (CCPP-UEPA), Belém, Pará, Brasil, Rod. Augusto Montenegro, } \\
\text { Km 03, s/n - Mangueirão, 66.640-000. E-mail: pesquimica04@ @mail.com. } \\
{ }^{3} \text { Doutor em Química (Físico-Química) pelo Instituto de Química de São Carlos (USP). Professor } \\
\text { Adjunto IV da Universidade Federal do Pará (UFPA), Belém, Pará, Brasil, Rua Augusto Corrêa, } 01 \text { - } \\
\text { Guamá, 66.075-110. E-mail: acfernandes@ @ufpa.br. }\end{array}$ \\
\hline
\end{tabular}


In view of the relevance that the supervised internship has in being the bridge between theory and practice, it is up to you to understand it as an essential curricular activity to the training process of undergraduate courses. Thus, the present study investigated whether the supervised internship carried out by undergraduate chemistry students at the Federal University of Pará (UFPA) is related to the idea of research aimed at the development of pedagogical activity as a means of building the professional profile of the teacher. Thus, it was investigated the realization of the internship within the initial and continuing training of teachers, in order to know it from a formative reality. Data collection took place through group discussion, based on a semi-structured interview, and the needs, anxieties and concerns about the training and supervised internship of the students were learned. In the analysis, it was noticed that the curricular component has contributed little to the training process and how important a differentiated approach is for it to be productive. Thus, the need for collaborative action by the triad is emphasized: Professor of the University - Professor in Training - Professor of Basic Education; so that it is possible to build a transformative practice from the beginning.

Keywords: Supervised internship. Teacher training. Chemistry teacher profile. Science Education. Chemical Education.

\section{INTRODUÇÃO}

O estágio docente é um componente da matriz curricular que possui profunda relação com a formação inicial e continuada de professores, porquanto, proporciona ao professor em processo formacional contato com o ambiente escolar, local da prática profissional. Sendo assim, pode-se dizer que as abordagens dessa atividade e o entendimento dela como ambiente de conhecimento pode refletir no perfil do discente em formação e orientar o ato de ensinar quando for um professor formado.

O estágio para e na pesquisa permite a promoção de reflexões e de considerações sobre o ser docente que, além de ser complexo por envolver inúmeros contextos, é a etapa na trajetória do professor pela qual ele aprende a ensinar e ensina enquanto aprende. $\mathrm{Na}$ literatura relacionada ao tema deste trabalho há relatos sobre o professor pesquisador e a inerência existente no ato de ensinar com o fazer pesquisa em educação, entretanto, é no exercício da prática docente que essa abordagem ganha significação e, que em certa proporção, influência o professor. Sendo assim, esta pesquisa foca no estudo da abordagem de estágio supervisionado para pesquisa e os reflexos à construção do perfil de Professores de Química na Universidade Federal do Pará (UFPA).

Vale salientar que muitos profissionais da educação, especificamente os que são da área de Ensino de Química, saem de sua graduação que o licencia a lecionar sem apresentarem vivências necessárias para solucionar os desafios presente no mundo educacional e que se 
fazem presente no ensino desta componente. Neste contexto, é na graduação e, preferivelmente, na realização do estágio que o futuro professor deve encarar os problemas, discuti-los, encontrar soluções e propor ações refletidas para o ambiente escolar e no contexto ensino e aprendizagem. Isto posto, buscou-se informações com a finalidade de encontrar respostas à problemática: $D e$ alguma forma, o desenvolvimento do estágio supervisionado se deu para pesquisa educacional e assim pôde refletir ou contribuir com o perfil do discente do curso de formação de professores de química da UFPA?

Entre os passos do presente trabalho para responder ao problema, busca-se identificar quais são os reflexos e as contribuições da (s) abordagem (ens) do estágio à formação do perfil docente. A próxima etapa foi verificar as concepções e relatos dos discentes sobre formação inicial e continuada de professores Críticos Reflexivos durante a realização da prática de estágio na UFPA.

\section{O ESTÁGIO SUPERVISIONADO NA CONSTRUÇÃO PROFISSIONAL INICIAL E CONTINUADA DE PROFESSORES}

A componente curricular estágio se caracteriza como esteio necessário à docência, define-se por ser constituinte obrigatória em cursos formativos de professores (pedagogias e licenciaturas). Neste contexto, o estágio abre diversas possibilidades de abordagens e finalidades que objetivam mudanças ao local de trabalho docente, a profissionalização, a construção identificativa docente e preparo para sua ação democrática (ALMEIDA; PIMENTA, 2015). O estágio adquire um papel relevante ao se conceituar dentro dessas perspectivas de tratamento que estão, evidentemente, preocupadas com o rumo educacional e com o preparo dos professores as questões conjecturais desse século.

Na visão de Almeida e Pimenta (2015), os discentes em processo formacional ao realizarem os estágios no decorrer da graduação, tornam-se perceptíveis ao contexto plural e suas relações, e assim podem propor variações de comportamentos pedagógicos, a realização de pesquisas e oportunidades que serão analisadas e reinterpretadas com a finalidade de levantar soluções frente aos problemas escolares. Por isso, o estágio ganha novos horizontes além propriamente do sentido técnico, da instrumentalização, o qual atribui ao ato de ensinar uma imagem simplista e de obediência a uma receita pronta.

É importante ressaltar que o estágio compreende atividade pela qual o discente observará a ação do professor da educação básica, isto é, seu diálogo com os estudantes, o 
modelo de ensino e, assim por diante. Não se pode pousar no campo das especulações, porém ir além, para, após um processo crítico-reflexivo, o campo prático. Finalmente, nesta ocasião das práxis no estágio que o graduando se conhecerá como um professor e se confrontando, e reelaborando seu fazer docente, transforma seu âmbito laboral. Ora, conforme explicado anteriormente, percebe-se a heterogeneidade existente no processo de ensino e aprendizagem e nesse sentido, fortalece a concepção de que uma formação adequada é imprescindível. Segundo Felício e Oliveira (2008), a componente curricular prática precisa no mínimo se revestir de estrutura e orientação para que intencionalmente favoreça a tal processo formativo.

Conforme verificado, não se pensa em estágio com uma visão dicotômica da teoria e prática, pois ao vincular a teorização no campo acadêmico com a realidade no trabalho escolar, é nessa orientação que dentro de sua respectiva área de atuação o licenciando estará em processo de habilitação para o ofício docente (PICONEZ, 2012). O autor deixa claro que, não se trata aqui de dominar os saberes produzidos no transcurso formativo sem o elo com o fazer na escola, ou seja, "agora a prática se dá na escola, nos estágios dos cursos de graduação, nos quais os professores vão procurar estabelecer um vínculo bastante forte entre o saber e o saber fazer" (CARVALHO, 2017, p. VI).

Diante do exposto, tem-se a concepção do estágio como momento de preparo docente e também (em decorrência de ação continuada) o espaço de reflexão em relação a práticaprofissional. Segundo Piconez (2012), o estágio é o momento teórico-prático em que as concepções de realidade escolar são reconstruídas e favorece a formação docente. Finalmente, ao afirmarem sobre o estágio compreendido dentro do conceito de práxis, a proposta de uma atividade transformadora é aquela "que aponta para o desenvolvimento do estágio como uma atitude investigativa, que envolve a reflexão e a intervenção na vida da escola, dos professores, dos alunos e da sociedade" (PIMENTA; LIMA, 2012, p. 34).

Então, o estágio assume importância inquestionável à docência, e é indispensável para tal. Sendo assim, a universidade, espaço onde ocorre o formativo de licenciandos, não deve minimizar esta prática ao mero treinamento, deve, porém, alavancar a preponderância por meio das pesquisas voltadas a essa temática (PIMENTA; LIMA, 2012). Em suma, conforme explicado, por meio de abordagens investigativas, por exemplo, as quais modelem a prática dos estagiários para um fazer pedagógico que evidencie melhora educacional, o estágio supervisionado poderá atender outras apelações que o ato de ensinar exige, porém são assuntos para os capítulos posteriores. Em Almeida e Pimenta (2015, p. 29) temos que: 


\begin{abstract}
Essa dinâmica é fruto das considerações teóricas que temos sobre o papel e a importância do estágio na formação de professores, pois acreditamos que para uma real aproximação com o futuro campo profissional é necessário que os estudante levantem dados, observem a prática de profissionais mais experientes, reflitam, analisem, conceituem, busquem articular as teorias estudadas com as situações práticas, procurem articular os vários elementos que estão percebendo na realidade observada de modo que avancem no seu desenvolvimento pessoal e na constituição dos seus estilos de atuação. Esse é o movimento que lhes permite, com o apoio das referências teóricas estudadas e das discussões realizadas em sala, buscar refletir criticamente sobre a realidade, interpretar o que observam e então, formular referências mais gerais para a prática futura. [...]
\end{abstract}

Dessa forma, espera-se que a componente curricular desempenhe na construção profissional dos professores perspectivas transformadoras das experiências de ensino, pois, para Pimenta e Lima (2012, p. 41) "o reducionismo dos estágios às perspectivas da prática instrumental e do criticismo expõe os problemas na formação profissional docente". O educador deve se ver como um agente social e influenciador na sociedade e, por assim dizer, um interventor no meio em que socializa (trabalho, universidade e entre outros); desta forma, o docente em formação por intermédio do estágio se contempla com tamanha responsabilidade, demonstrando-se a sua relevância em aproximar o licenciando do âmbito profissional de atuação.

\title{
2.1 A LEGISLAÇÃO EDUCACIONAL E O ESTÁGIO SUPERVIONADO
}

O estágio docente é definido e regulamentado pela Lei $n^{\circ} 11.788 / 2008$ e a Resolução ${ }^{\circ}$ 2 , de $1^{\circ}$ de julho de 2015 , respectivamente, a qual o conceitua da seguinte maneira: "O estágio curricular supervisionado é componente obrigatório da organização curricular das licenciaturas, sendo uma atividade específica intrinsecamente articulada com a prática e com as demais atividades de trabalho acadêmico" (BRASIL, 2015, p. 12). Segundo Pimenta e Lima (2018) esta resolução aborda não só o cenário formativo inicial, porém o de formação continuada dos professores, referindo-se assim às mudanças presentes no âmbito educacional.

Desse modo, verifica-se, por exemplo, que as cargas horárias destinadas a formação de professores nas instituições superiores aumentaram e, consequentemente, a carga horária definida para o estágio passou a ser de 400 horas. Sendo assim, para Carvalho (2001), esse montante de horas deve ser esboçado a propor o maior aproveitamento do que será realizado durante o estágio docente, das atividades sejam elas de observação até a pesquisa no estágio. 


\begin{abstract}
Não podemos discutir as mudanças que devemos fazer na formação dos professores de Biologia, Física e Química, principalmente se quisermos abordar os estágios de nossos alunos nas escolas fundamental e média, sem primeiro olhar a influência que elas estão sofrendo a partir da nova legislação - a Lei de Diretrizes e Bases da Educação, LDB -, dos novos pareceres do Conselho Nacional de Educação, dos novos parâmetros curriculares e dos novos projetos pedagógicos. É tanta novidade que os professores, de todos os níveis, estão bastante inseguros sobre o que ensinar e como ensinar (CARVALHO, 2001, p. 113).
\end{abstract}

Conforme citado, pode-se dizer que é importante compreender o estágio dentro dessa perspectiva legal, dado que, à vista disso há um delineamento de como a prática deverá ser realizada. Diante dessas mudanças, fica claro que, as concepções legais podem, se não acompanhadas de modo crítico, reduzir o significado do estágio e comprometer a sua adequada organização, quanto o entendimento do estágio como componente curricular (PIMENTA; LIMA, 2018).

Logo, torna-se imprescindível contemplar o estágio docente como uma fase fundamental na trajetória formativa do professor e da composição curricular da área de ensino, o que só pode ser possível se a legislação educacional for construída com a participação de agentes indispensáveis neste processo. Nessa linha, acredita-se que o modelo estabelecido de constituição do professorado brasileiro ainda tem sido um dos principais entraves quanto ao que se deseja em relação a melhorias no âmbito educacional, decerto, o estágio supervisionado compreende parte relevante na conjectura inicial e continuada à docência. Em face disso, compete as políticas públicas a serem introduzidas possam expressar, democraticamente, o que se espera dos discentes - futuros educadores.

\title{
2.1.1 O ESTÁGIO NA UNIVERSIDADE FEDERAL DO PARÁ (UFPA)
}

A Resolução n. 4.262, de 22 de março de 2012, é o documento oficial que regulamenta a realização dos estágios curriculares nos cursos de graduação da UFPA. Diante disso, compreende-se que as instituições de Ensino Superior possuem autonomia quanto a essa função e, neste caso, tal regulamento contém princípios norteadores, concepções, natureza e modalidades e objetivos. A coordenadoria de mobilidade, estágio e bolsas da Universidade Federal do Pará possui uma plataforma online conhecida como central de estágio que contempla todas as informações, legislações e uma base de cadastro referente a essa componente da matriz curricular. Com relação aos princípios do estágio regidos pela UFPA: 
Art. $1^{\circ} \mathrm{O}$ Estágio Supervisionado dos Cursos de Graduação e de Educação Profissional da Universidade Federal do Pará (UFPA) obedecerá aos seguintes princípios:

I - articulação da formação acadêmica com o exercício profissional; II - efetiva participação do aluno em situações reais de trabalho; III - fortalecimento da integração entre ensino, pesquisa e extensão (UFPACONSEPE, 2012, p. 2).

A grade curricular do curso de Licenciatura em Química da UFPA define que a primeira atividade de estágio deve ser desenvolvida a partir do quinto semestre (bloco 5), sendo denominada de: "Vivências Pedagógicas no Ensino Fundamental". As outras três vivências pedagógicas são realizadas na $1^{\mathrm{a}}, 2^{\mathrm{a}}$ e $3^{\mathrm{a}}$ séries do Ensino Médio. No Projeto Pedagógico do Curso (PPC), a disciplina de estágio supervisionado integra o núcleo profissional que constitui uma parte do conjunto de atividades curriculares do curso. Com relação aos estágios relativos à Licenciatura em Química da UFPA:

Art. $6^{\circ}$ Os estudantes deverão integralizar, no mínimo, 400 (quatrocentas) horas de Estágio Curricular Supervisionado, que deverão ser exercidas em Escolas de Ensino Fundamental e Médio da Rede Pública e/ou Privada, sob a supervisão de professores pertencentes à Faculdade de Química, ou autorizados, e acompanhados por professores da própria escola onde se realizará o estágio, que terá o seu início a partir do $5^{\circ}$ semestre do Curso (UFPA-CONSEPE, 2010, p. 2).

Conforme citado, verifica-se que a instituição elabora documentos sobre a composição do estágio da Licenciatura em Química, além disto, encontra-se uma pequena diferença na carga horária que em âmbito nacional foi definida e o que se apresenta no PPC dessa licenciatura: “Art. $9^{\circ}$ [...] II - 408 (quatrocentas e oito) horas de estágio curricular supervisionado" (UFPACONSEPE, 2010, p. 3). Então, assim é delimitado o estágio voltado a formação de licenciados em química da UFPA.

\section{METODOLOGIA}

A pesquisa teve como local eleito para sua realização a Universidade Federal do Pará (UFPA), no campus de Belém, no bairro do Guamá. A instituição de Ensino Superior é referência na formação de profissionais na localidade, inclusive, profissionais docentes, os quais atuarão para suprir a demanda de professores na região metropolitana de Belém e no restante do Estado. Os discentes de licenciatura da referida instituição possuem vivências em 
diversos contextos escolares presentes no Estado do Pará e, portanto, são sujeitos de pesquisa que podem contribuir com a obtenção de resultados relevantes e que reflitam a realidade formativa da região. Assim sendo, nesta instituição, encontram-se relativamente a amostragem que represente as características estudadas na localidade e, que posteriormente, poderá ser ampliada para outros contextos regionais.

A presente pesquisa foi desenvolvida com oito alunos de uma mesma turma de formandos em Licenciatura em Química da UFPA, e buscou por meio da Discussão em Grupo com esses Licenciandos compreender o papel do estágio na construção do perfil docente, no tocante a graduação nessa IES. Tendo a pesquisa sido realizada no dia 29 de novembro de 2018, e para efeito de análise, as verbalizações dos discentes foram transcritas com o propósito de se ter um entendimento sistemático das considerações feitas acerca da temática em estudo.

Com relação à atividade de estágio, elegeu-se para esta pesquisa os discentes de graduação que estavam no último semestre, isto por que eles já concluíram três estágios supervisionados, portanto, considera-se que apresentam certa vivência. O quarto e último estágio supervisionado dá-se na $3^{\mathrm{a}}$ série do Ensino Médio. Dentre a turma, buscou-se a participação dos alunos que ingressaram no curso em 2015, pois compreende-se que tais alunos passaram por mudanças relevantes durante o transcurso da grade curricular nesses quatro anos de graduação e se espera que contribuam com uma postura crítica frente as experiências que norteiam o seu processo formativo.

No grupo de discussão foram utilizadas algumas perguntas para encaminhar o debate e, assim, os discentes fossem levados a refletir sobre o desenvolvimento dos estágios durante o período formativo da graduação e, destarte, suscitar respostas direcionadas ao alcance dos objetivos propostos. Na ocasião, foi elaborado um planejamento contendo as perguntas feitas, sendo também feitos novos questionamentos no decorrer da pesquisa, com o propósito de avaliar, especificamente, como se deu o desenvolvimento das práticas de estágio.

O planejamento possibilitou a elaboração da pesquisa em três blocos de debate, os quais foram arquitetados com a finalidade de se obter por meio da proposição de perguntas norteadoras, preestabelecidas, e de outros questionamentos feitos durante o procedimento, a extração das mais variadas considerações dos formandos com relação ao eixo da investigação. O primeiro bloco foi voltado a perguntas relativas ao cenário formativo da Licenciatura em Química da UFPA. O segundo com questões destinadas a componente estágio do referido curso de graduação, nesse caso, relato das vivências e das atividades executadas. No terceiro bloco, 
as perguntas foram orientadas sobre a maneira como o estágio tem sido aproveitado e abordado no curso, buscou-se identificar de que forma foi contributivo a disciplina no decorrer de sua formação, dentro da concepção do que seria ser professor para os discentes.

É válido lembrar que, a análise das informações é de caráter qualitativo e, classifica-se de modo exploratório e descritivo, outrossim, o método analítico é o hipotético-dedutivo. A partir da análise dos discursos, deu-se a articulação de inferências, relacionadas com o alcance dos objetivos pretendidos, e se possível propor novos estudos e novas considerações que contribua para o seu público alvo.

Os formandos se posicionaram, aleatoriamente, em um círculo, no qual o mediador e pesquisador tomou posição central e orientou a discussão a respeito do estágio supervisionado e de sua contribuição na construção do perfil docente. $\mathrm{O}$ grupo de discussão foi submetido a interrogações previamente escolhidas, porém, devido a algumas reações distintas, houve novos direcionamentos, com fins de possibilitar a captação adequada de informações relativas à proposta do estudo. Isto posto, ressalta-se que o estudo partiu de uma perspectiva mais geral que corresponde ao contexto inicial da formação docente, e se seguiu até questões relativas a temática estágio. Do mais, os discentes foram definidos como A1, A2, A3 e assim sucessivamente.

\section{EXPOSIÇÃO E ANÁLISE DOS DADOS}

Os dados coletados sob toda a perspectiva metodológica desenvolvida nesta pesquisa, após serem transcritos e analisados, passaram por recortes como forma de se adequar a pesquisa, a qual parte de discussões mais gerais até as mais específicas.

\subsection{CONCEPÇÕES DOS DISCENTES ACERCA DO ESTÁGIO SUPERVISIONADO}

No estudo, buscou-se compreender as percepções construídas pelos estudantes acerca do estágio e como eles o caracterizam, para tanto, perguntou-se: Como os discentes em formação concebem estágio supervisionado, quais considerações eles têm sobre o que é a componente e seu papel para sua formação? 
O estágio supervisionado nem deveria se chamar "estágio supervisionado", para começo de conversa, porque não tem nada de supervisionado aí e, deveria se chamar estágio obrigatório, somente; porque a única coisa que a gente tem é quantitativa, os professores que a gente tem tido até agora no estágio supervisionado como nossos orientadores, porque de orientação não vejo muita coisa, eles só querem que a gente leve a lista de presença (A6).

[...] por que teoricamente o que seria o estágio supervisionado: seria um treinamento do que a gente vai ser, só que a gente não consegue fazer esse treinamento por que o professor fala uma coisa dentro da universidade e chega lá na escola o professor que nos moldar de uma forma diferente, [...] (A8).

Nos recortes, verifica-se como concepção de estágio que: é um treinamento de como ser professor, ou seja, a redução da prática docente a apenas treino de como ensinar, ou melhor, sob essa óptica, transmitir conteúdos de química para os alunos.

O discente A4 revela um contrassenso entre o docente universitário e o professor da educação básica, conforme fragmento abaixo:

Eu concordo com o que eles falaram e, que o estágio supervisionado é uma maneira de antecipar sim dentro do nosso curso, para quê? Por exemplo, aqui dentro do curso a gente é bombardeado de teorias pedagógicas, de métodos de como "dar aulas", mas quando a gente para poder vivenciar isso daí, quando a gente vai para a prática lá no estágio, a gente verifica que boa parte do que, teoricamente, a gente teve aqui dentro do curso, não se aplica, não dá certo, mas por que isso não dá certo? Na minha opinião, [...] por que a universidade se encontra muito distante da realidade da escola, porque aqui dentro da universidade tu tens m mundo idealizado e lá dentro da escola não, lá tu tens a realidade nua e crua $[\ldots]$ (A4).

As considerações apresentadas demonstram que os alunos possuem concepções não tão distintas acerca de estágio, e tais foram unânimes em declarar que não se deveria entendê-lo como supervisionado, mas sim como uma componente obrigatória, devido à falta de supervisão durante sua realização. Nesse sentido, salienta-se que um dos motivos que levaram a essa colocação relaciona-se a questão da distância existente entre a IES e as escolas que, dificulta o acompanhamento pelo orientador da componente curricular in loco, porquanto, são vários discentes espalhados pelas mais diversas instituições escolares da Rede de Ensino do Estado do Pará. Além disso, segundo os licenciandos, em muitas ocasiões não foi possível transpor as barreiras impostas pelo sistema educacional brasileiro, e muito deve-se a falta de conexão entre os discursos ou visões de cada integrante da tríade da prática de estágio, isto é, o professor em formação, o orientador da componente curricular na IES e o professor da escola em que foi realizado o estágio. 
De modo geral, o que se percebe na maioria das falas, é o quanto o estágio está longe do que eles esperaram que fosse, observa-se mais comentários de como o estágio não deveria ser do que, em tese, espera-se que seja. Diante desses relatos, o momento de realização da atividade de estágio supervisionado docente não tem sido um ambiente à formação docente.

É possível inferir que, por ser um campo de conhecimento, a realização do estágio engloba diversos aspectos que se relacionam profundamente com a pesquisa no estágio e se caracteriza pelo processo reflexivo sobre todas as etapas que envolve o estágio em seu complexo contexto (ALMEIDA; PIMENTA, 2015). Assim sendo, tal concepção acerca do estágio promove uma ressignificação na forma de abordagem e de encará-lo como atividade formativa pelos próprios licenciandos. E por assim dizer, não o compreender desta forma acarretará o que se observa nos discursos dos discentes, ou seja, o que estágio supervisionado não deveria ser.

\subsection{CONTRIBUIÇÕES DO ESTÁGIO PARA O EXERCÍCIO DOCENTE}

No planejamento se previa que os formandos discutissem sobre a satisfação com relação a componente de estágio supervisionado. A questão que se fomentou foi: Até que ponto o estágio supervisionado contribui para o exercício docente e se essa contribuição tem sido satisfatória?

[..] no estágio supervisionado a gente vai para a prática de verdade, só que não é muito assim, por exemplo no meu estágio supervisionado eu passei o estágio todo sentada numa cadeira, a única coisa que o professor fez foi me apresentar para a turma. Mas é só o que tu fazes, tipo é para a gente observar? Sim! Mas a gente não tem nem um pouco de interação com o aluno, nem com o professor e nem com os alunos, lógico que não é muito contributivo. Nesse sentido, eu acho que foi pouco satisfatório (A6).

No fragmento, o discente descreve algumas de suas experiências de estágio, as quais revelam momentos de não aproveitamento dessa atividade para fins formativos, tanto para o licenciando, como para o professor que está em formação contínua.

Em relação as contribuições do estágio supervisionado eu acredito que tive contribuições sim, justamente por que os professores acabaram sendo contraexemplos para mim a partir dos erros que pude observar, refletir e perceber que não quero fazer aquilo lá que fazia com os alunos deles (A7). 
Com relação a importância dos estágios na nossa atividade docente, como a A7 falou, pra mim serviu como contraexemplo, como um exemplo que a gente não deve seguir com relação ao processo de ensino aprendizagem numa escola. Mas aí depois fiquei pensando que, e se nós não tivéssemos um espaço não formal? E se estágio fosse no segundo semestre, pensaríamos da mesma maneira? Ao assistir as aulas dos professores será que teríamos a capacidade de criticar? [...] não lembro o autor agora, acho que o Maldaner, que fala que nós temos a tendência de ensinar da maneira que fomos ensinados, [...] se eu não tivesse vivências em espaços não formais de ensino, com certeza estaria reproduzindo o que vi nos estágios (A5).

Diante do exposto, verifica-se que os discentes atribuem contribuições ao estágio, os quais classificam como: contraexemplos e de desconstrução (do perfil do docente em atuação). Porém, um deles destaca um ponto relevante, que diz respeito a esta postura crítica; sua possibilidade é fruto de vivências em outros espaços.

[...] se tratando de estágio supervisionado posso afirmar que, de forma bem tranquila e sem nenhuma culpa, que o estágio supervisionado não contribui praticamente em nada, em ser um professor diferenciado dos que já estão aqui no mercado hoje, na atualidade (A4).

Os formandos em Licenciatura em Química evidenciam que a disciplina estágio tem se mostrado um meio reflexivo em relação a condução da prática docente. Sendo destacado como tem se constituído a ação docente (como contraexemplos) dos atuais professores nas escolas, de realização dos estágios. No contexto do estágio supervisionado, caso não se tenha o devido cuidado, os futuros educadores, inevitavelmente, recaem na "imitação" de um modelo (MALDANER, 2006).

\subsection{FOCO NA REALIZAÇÃO DA ATIVIDADE DE ESTÁGIO}

O que se observou durante a discussão, é que o estágio promovido no curso de Licenciatura em Química da UFPA possui uma postura distante do que se espera para a componente curricular tanto pelos alunos quanto pelo o que diversos autores o definem. Os discentes comentaram que as contribuições para os tornarem crítico/reflexivo foram poucas, ou quase nenhumas, eles criticaram a forma como são "supervisionados", sem o devido acompanhamento do professor nos principais procedimentos realizados da prática.

O professor vê a turma de estágio supervisionado como um organismo homogêneo, mas a turma que está realizando o estágio, quem está praticando o estágio na turma, ela não é um organismo homogêneo, por exemplo, a A7 tem suas especificidades, as dificuldades dela, assim como tenho as minhas [...], o professor, ele deveria estar mais 
próximo do aluno no momento do estágio, porque no meu ponto de vista, o estágio supervisionado é um momento ímpar, mais especial dentro da formação de professores [...] (A4).

Neste recorte, percebe-se na visão deste docente em formação como o professor formador contempla os discentes, que neste caso, não considera as especificidades de cada aluno. Além disso, ele relata a existência de um distanciamento do professor orientador do docente estagiário. Entretanto, deve-se considerar que é inviável o professor acompanhar vários alunos em cada escola que estiver um discente sob sua orientação, a Escola de Aplicação da Universidade Federal do Pará (UFPA) deveria facilitar essa supervisão, mas o que se observa são os alunos em sua grande maioria escolhendo atuar em outras unidades de ensino. O modelo de supervisão de estágio pode não está sendo eficaz, mas isso se deve por variados fatores, os quais podem ser de natureza da carga-horária de trabalho docente, ou de natureza curricular.

[...] sendo que essa oportunidade [de discussão e mudanças]deveria nos ser dada no estágio supervisionado ou ao fim, ou no meio, e aí o que vocês estão achando do estágio supervisionado? Abram suas críticas, a gente fez isso algumas vezes na sala de aula, mas o professor só pergunta o que vocês estão achando e nem pergunta como a gente pode contribuir, o que a gente pode mudar, bora mudar? Não existe essa proposta. A gente só reclama! (A6).

Os conhecimentos destacados pelos alunos, em face do que observam a respeito do modelo de estágio, há destaque às visões dos professores formadores, as discussões relativas a disciplina e as experiências que deveriam produzir, as quais são expressas como pouco significativas. Desse modo, compreende-se que os formandos não veem a componente como cooperante a sua formação profissional, porque o método de realizar estágio não é o que deveria ser segundo o que foi destacado na presente pesquisa, o estágio na pesquisa e para pesquisa. Os alunos destacam que se há influência ao ser professor crítico/reflexivo, não advém de tal componente curricular.

[...] os dois estágios, o um e o quatro até agora, nenhum me favoreceu a reflexão até agora, o que eu aprendi sobre professor reflexivo, sobre o que é fazer reflexões da nossa prática, do nosso ato, das nossas aulas e dos nossos planejamentos eu aprendi com minhas práticas no clube de ciências e em outros espaços (A3).

Segundo Carvalho (2017, p. VII), "precisamos criar professores reflexivos, mas essa reflexão não se faz sem a busca de referenciais teóricos, [...] ou daqueles que relacionam os 
acontecimentos em sala de aula com o espaço escolar e a sociedade como um todo". O que se percebe é que não acontece nos estágios essa inserção de teorias e a sua relação com o que acontece no espaço escolar e no contexto em que é inserido. Sobre a realização da atividade de estágio neste molde, Pimenta e Lima (2012, p. 186) afirmam que:

Os esquemas tradicionais de realização de estágios sob a forma de observação, participação e regência, tendo por pressuposto que a aprendizagem de ser professor se dá pela reprodução das práticas observadas e experimentadas, revelam seu esgotamento em decorrência da verificação de que essa modalidade não resulta em melhoria dos resultados do ensino, pois a concepção que a sustenta é a de que o ensino é uma atividade técnica que, uma vez aprendida, pode ser aplicada em qualquer situação.

Conforme citado, é imprescindível mudança no modo de supervisionar, de se realizar estágio e discuti-lo na Universidade, assim como discutir as experiências docente, de modo aprofundado, proporcionada nesta atividade. Cabe uma sugestão: à realização do estágio supervisionado de acordo com as orientações descritas no artigo das professoras Silva e Schnetzler (2008), são propostas de organizar uma supervisão eficaz e propor atividades formativas durante o estágio.

\subsection{SOBRE OS PLANOS DE ESTÁGIO}

O planejamento esboça a sua relevância no modelo organizacional das ideias, reforça a autonomia e intencionalidade de quem o faz, além de expressar a objetividade do fazer mediante o pensar. "O ideal é que o estagiário faça um plano de estágio que envolva de uma forma integrada todas as atividades de estágio: [...]" (CARVALHO, 2017, p. VII). Os alunos foram questionados sobre a elaboração de planos de estágios, de planejamento das atividades que seriam desenvolvidas no estágio.

Em relação ao planejamento, eu não tive a oportunidade de estar realizando planejamentos durante o estágio, acredito muito devido a questão de o professor ser muito fechado, o professor não tem um interesse de estar conversando com o aluno, não há proximidade, e a falta dessa proximidade acaba dificultando a construção desse planejamento. Assim como, também, o próprio professor orientador da atividade de estágio que também ele é distanciado do aluno que está praticando o estágio e isso vem contribuir de forma decisiva para a falta desse planejamento (A4). 
Os alunos se demonstraram surpresos ao serem questionados sobre realizar um plano de estágio para colaborar nas vivências e realizar no estágio pesquisa de sua prática. Alguns destacaram o porquê de não ter elaborado um planejamento, que tem por motivo o distanciamento entre os três sujeitos indispensáveis nesta produção - professor supervisor, professor orientador e professor estagiário.

É evidente que essa falta de planejamento, a forma de abordagem da atividade de estágio elucidadas pelos discentes dá a impressão que o estágio não é realizado para a pesquisa e na pesquisa, tratando-se da Licenciatura em Química da UFPA. É necessário considerar como um dos motivadores da insatisfação dos discentes com relação a componente e a explicação deles não a considerarem formativa. Em diálogo com professores formadores em nível nacional, Lima e Pimenta (2012, p. 181) afirmam que:

\footnotetext{
Percebemos, ainda, que nas reuniões de planejamento na universidade, a formação de grupos de estudos e pesquisas voltadas para o estágio não é de fácil viabilidade. Os problemas com a unanimidade dos docentes em torno da operacionalização de um projeto pedagógico do curso de formação de professores e, em decorrência deste, de um projeto de estágio, envolvem fatores que estão além da dimensão didáticopedagógica. Envolve a forte desvalorização da docência na graduação e, em consequência, do estágio.
}

Os resultados desse quadro são devido a inúmeros fatores, os quais se relacionam a motivações dos professores formadores com a construção da grade curricular, com a concepção do professor da escolar, com a vontade do discentes em formação, mas, principalmente, a falta de mudanças significativas na formação inicial de professores. Por isso, fica evidente que o estágio formativo com base no padrão vigente pouco contribui, espera-se, dessa forma, que a atividade seja observada dentro de perspectivas altamente formativas para promover a construção do perfil docente.

\section{CONSIDERAÇÕES}

Pode-se verificar conforme o prosseguimento dos discursos e de sua análise, que o estágio no curso de Licenciatura em Química da UFPA, não é abordado para a pesquisa e na pesquisa, pois de acordo com os relatos de como a atividade foi realizada, as considerações sobre o despreparo para o exercício docente e dos distanciamentos entre os sujeitos integrantes da tríade de estágio, propõe uma prática afastada do cunho investigativo. Os formandos 
atribuíram contribuições a outros espaços formativos em detrimento do estágio supervisionado, pois o mesmo não refleti de modo significativo o perfil do discente em formação da UFPA, e tal prerrogativa se confirma nas duras críticas e reações que eles fizeram e demonstraram ao discorrer sobre o estágio e sua formação inicial na instituição. Em geral, descreveram suas experiências de estágios como meras observações, encontros e discussões improdutivas na Universidade e conflitante com relação ao exercer a docência inicial nas escolas em que estagiaram, os mesmos fizeram questão de salientar que eram desvalorizados em certa parte pelos estudantes e pelo professor no ambiente de atuação do estágio

A partir do diálogo, observou-se que os discentes estavam descontentes com o processo de formação inicial e como o estágio supervisionado se mostrava ineficiente a partir do modelo praticado. Neste sentido, indubitavelmente, faz-se uma profunda relação da prática de estágio com a formação de professores o, que se pode inferir, de acordo com as verbalizações dos discentes do grupo de discussão, quando afirmam que tanto a formação quanto o estágio não foram e nem têm sidos satisfatórios. Alguns alunos já atuam na docência e, portanto, o estágio assume um papel importante na formação continuada de professores, o que, muito provavelmente, seria relevante por motivos semelhantes aos que os alunos se referiam quando esboçavam suas opiniões sobre a formação inicial.

Por meio do estudo, buscou-se concepções acerca do estágio, conceitos que os alunos pudessem expressar durante a discussão que, fica evidente, nas falas deles, o que tem sido estágio dentro de suas experiências, e não o que deveria ser. Apenas um discente pôde revelar sua preocupação com o que seria estágio, e que buscou pesquisar na ementa da disciplina que se constituía como atividade. Percebeu-se que os alunos mostravam poucos conhecimentos sobre a legislação de estágio e a carga horária que deveriam exercer de atividade prática, bem como, alguns o reduziram a treinamento da docência.

Com base no que o grupo discutiu, pode-se perceber o quanto eles tomaram posturas reflexivas, críticas e de resistência com relação a forma como o estágio vem sendo tratado no curso. Apresentaram tal posicionamento e reconheceram que tal característica era fruto de vivências em espaços diferenciados de formação de professores e experiências em outros ambientes docentes e, não fruto do que o estágio deveria proporcionar. Os docentes em formação inicial comentaram que se sofressem influência das práticas vividas nos estágios, seriam como tais professores, fechados e tradicionalistas em seu modo de ensinar. Isto posto, os futuros docentes revelaram que o estágio não foi um momento que os ajudou a conhecerem 
a escola e seus contextos, não tiveram contato com o Projeto Político-Pedagógico da escola (PPP), com o seu regimento e, também, que não os ajudou a ter familiaridade com as ferramentas de auxílio pedagógico, porque é visível a falta de planejamento das atividades de estágio e de postura investigativa nele. Os alunos não tiveram a oportunidade de realizar pesquisa durante o estágio supervisionado e nem mostraram conhecimento sobre tal metodologia para a atividade curricular.

Vale destacar que, durante o processo investigativo, os formandos, participantes da pesquisa, foram convidados a classificarem as disciplinas que tiveram contribuição formativa e, dentre as quatorze componentes citadas, o estágio não foi destacado. É interessante ressaltar que a atividade tem teor formativo elevado, pois promove a participação do futuro docente no ambiente escolar, não foi considerada entre as disciplinas que se organizam, informalmente, como de conhecimentos didáticos-pedagógicos sobre o ensino de Química e específicas da área da Química. Além disto, o quanto os espaços não formais de ensino foram citados como ambientes que mais contribuíram para os estudantes no que tange a sua formação. Expõe-se o quanto são necessárias mudanças no modo em se realiza o estágio, o quanto a matriz curricular precisa sofrer mudanças e que a universidade tem um papel preponderante nessas transformações, visto que, necessita ter uma preocupação com o tipo de profissional, a qualidade dele e o preparo que ele deve ter e receber no centro de formação.

É importante que o professor formador que assuma a orientação da atividade de estágio repense sua prática, organize-a, planeje-a e desenvolva de modo que possa aproximar o discente em formação de sua futura realidade profissional. Sugere-se a leitura de livros voltados a relação estágio supervisionado e os cursos de licenciatura como forma de auxiliar o professor em exercício e o licenciando, com vistas a promoção de experiências no percurso formativo. Além do mais, os discentes sugeriram mudanças nas práticas pedagógicas, no momento em que o estágio se inicia no curso, ou seja, segundo eles deveria começar desde o primeiro semestre e, que em um dos estágios fosse exigida a realização de atividades em espaços não formais de ensino e também de disciplinas como, por exemplo, laboratório interdisciplinar no ensino de química. Em nosso entendimento, o estágio não tem condições de iniciar nos primeiros semestres por compreender que os discentes ainda possuem os conhecimentos necessários em relação a prática de ensino e aprendizagem. 


\section{REFERÊNCIAS}

ALMEIDA, Maria Isabel de; PIMENTA, Selma Garrido. Estágios supervisionados na formação docente: educação básica e educação de jovens e adultos. São Paulo: Cortez, 2015. BRASIL. Resolução CNE/CP $n^{\circ} 2$, de $1^{\circ}$ de Julho de 2015. Define as Diretrizes Curriculares Nacionais para a formação inicial em nível superior (cursos de licenciatura, cursos de formação pedagógica para graduados e cursos de segunda licenciatura) e para a formação continuada. Brasília, Jun. 2015. Disponível em: http://portal.mec.gov.br/index.php?option=com_docman\&view=download\&alias=136731rcp002-15-1\&category_slug=dezembro-2019-pdf\&Itemid=30192. Acesso em: 15 nov. 2018.

CARVALHO, Anna Maria Pessoa de. A influência das mudanças da legislação na formação dos professores: as 300 horas de estágio supervisionado. Ciência \& Educação, São Paulo, v. 7, n. 1, p. 113-122, 2001. Disponível em: http://www.scielo.br/scielo.php?pid=S151673132001000100008\&script=sci_artte. Acesso em: 16 nov. 2018.

CARVALHO, Anna Maria Pessoa de. Os estágios nos cursos de licenciatura. $1^{\mathrm{a}}$ ed. São Paulo: Cengage Learning, 2017.

FELÍCIO, Helena Maria dos Santos.; OLIVEIRA, Ronaldo Alexandre de. A formação prática de professores no estágio curricular. Educar, Curitiba, n. 32, p. 215-232, 2008. Disponível em: http://www.scielo.br/scielo.php?pid=S010440602008000200015\&script=sci_arttext\&tlng=pt. Acesso em:16 nov. 2018.

MALDANER, Otávio Aloisio. A formação inicial e continuada de professores de química: professor/pesquisador. $3^{\text {a }}$. ed. Ijuí: Unijuí, 2006.

PICONEZ, Stela C. Bertholo. A prática de ensino e o estágio supervisonado. $24^{\mathrm{a}} \mathrm{ed}$. Campinas: Papirus, 2012.

PIMENTA, Selma Garrido; LIMA, Maria Socorro Lucena. Estágio e docência. 7a . ed. São Paulo: Cortez, 2012.

PIMENTA, Selma Garrido; LIMA, Maria Socorro Lucena. Estágio e docência. $1^{\mathrm{a}}$. ed. São Paulo: Cortez Editora, 2018. E-book (390 p.). (Coleção docência em formação:ensino superior). e-ISBN 978-85-249-264-7. Disponível em:

https://books.google.com.br/books?hl=pt-

BR\&lr=\&id=NXdZDwAAQBAJ\&oi=fnd\&pg=PT2\&dq=info:iRESr7oHWUYJ:scholar.googl e.com/\&ots=BvnMdhyyap\&sig=f40k6-Sc11JlmEBXwkFL3f-Lu20. Acesso em: 14 nov. 2018. 
SILVA, Rejane Maria Ghisolfi da; SCHNETZLER, Roseli Pacheco. Concepções e ações de formadores de professores de Química sobre o estágio supervisionado: propostas brasileiras e portuguesas. Química Nova, v. 31, n. 8, p. 2174-2183, nov., 2008. ISSN 2174-2183.

Disponível em: http://www.scielo.br/scielo.php?pid=S0100-

40422008000800045\&script=sci_arttext. Acesso em: 12 nov. 2018.

UNIVERSIDADE FEDERAL DO PARÁ. Conselho Superior de Ensino, Pesquisa e Extensão (CONSEPE - UFPA). Resolução n. 3954, de 24 de março de 2010. Projeto Pedagógico do Curso de Licenciatura em Química. Belém: CONSEPE, 2010. Disponivel em:

http://sege.ufpa.br/boletim_interno/downloads/resolucoes/consepe/2010/3954\%20PPC\%20Li c\%20Quimica.pdf . Acesso em:15 nov. 2018.

UNIVERSIDADE FEDERAL DO PARÁ. Conselho Superior de Ensino, Pesquisa e Extensão (CONSEPE - UFPA). Resolução n. 4.262, de 22 de março de 2012. Regulamento dos Estágios Supervisionados, Obrigatórios e Não Obrigatórios, dos Cursos de Graduação e de Educação Profissional da UFPA. Belém: CONSEPE, 2012. Disponível em:

http://www.centraldeestagios.ufpa.br/view/inicio/downloadArquivo?idArquivo=16. Acesso em: 15 nov. 2018.

Submetido em: 15 de maio de 2020 . Aprovado em: 23 de junho de 2020. 